\title{
A New Frame Work of Real-Time Charaterization Battery Platform
}

\author{
Hamid BENTARZI(1)*, Mahdi Abdenour LITOUFI(1), Nazim TAIR(1),Tarek AZZOUNI(2) \\ (1) Laboratory Signals and Systems (LSS), IGEE, University M'hamedBougaraBoumerdes, Algeria \\ (2) dept. of Physics, FS, University M'hamedBougaraBoumerdes, Algeria \\ *Corresponding author e-mail: h.bentarzi@univ-boumerdes.dz
}

\begin{abstract}
:
Batteries play an important role in the performance enhancement of power grids including renewable energy systems. In order to attain the rated service life and the longest possible run time of a battery, it is necessary to be monitored and maintained. This needs for an effective real-time characterization platform. Therefore, this paperpresents a new frame work of a real-time battery monitoring system that will be able to provide the user with battery parameters as well as a recording file of the instantaneous variables values. To perform this task, a PC based platform associated with acquisition board is developed to automate the battery characterization system.

A graphical user interface (GUI) that allows users to read the Open Circuit Voltage (OCV), current, and ambient temperature of the battery during its charging or discharging is developed using Labview software. It is easy and possiblefor data to be recorded, including voltage, current, during both charging and discharging process. These recording experimental data can be used for a precise and efficient estimation of the state of charge as well as for aging study.
\end{abstract}

Keywords: Battery, Modelling, CharacterizationMethods, State of Charge.

\section{INTRODUCTION}

Resources of an alternative energy such as renewable energy systems have been developed many years ago, which can easily replace fossil energy in many applications. Since the electrical power generated by solar and wind generators is not stable and is affected by changes in meteorological conditions. Thus, energy storage device at the site of power generation, as well as the smart grid, is required to stabilize the power system and store excess energy properly and efficiently. Energy storage systems, play an important role in power grid performance enhancement, however, it is difficult to store electrical energy for long time without change. Generally, batteries may be used as energy storage systems in Electric Vehicles (EV), Uninterruptible Power Supplies (UPS), renewable energy systems, and cordless electric power tools applications.

Since the electrochemical ESS (Battery) is complex, its parameters or energy storage capacity cannot directly be measured by any sensor, this makes it difficult to develop an efficient estimator of SOC in real-time. So, the Coulomb Counting is the most common method. A simple algorithm for the product of current and charge or discharge time is used to measure residual capacity. This approach is more accurate when temperature, charging and discharging efficiencies are considered [1]. However, the initial SOC cannot be estimated because it is dependent on sensor precision. Furthermore, these errors will be significant with time. The measurement of open-circuit voltage (OCV) is a more precise method for determining SOC. OCV can be determined when there is no load, this approach is suitable for calculating the initial SOC. However, the battery is not in an open circuit state during charging or discharging process. The OCV should ideally be obtained after the battery has been idle for more than ten hours [2]. Ambient temperature is a significant factor that affects the precision of battery SOC estimation, this latter can result in errors in battery SOC estimation.

Characterization methods developed in recent years have shown to be important for optimizing battery materials, understanding cell degradation mechanisms, and eventually enhancing overall battery performance. Researchers can better understand the battery process and create better battery systems by developing and applying enhanced characterization techniques.

Since the improvement of batteries, due to the fast growth in their applications, particularly multimedia applications like smartphones, PCsand tablets, is necessary. Engineers and inventors are still working on improving the performance of these 
batteriesand hence their efficiency and durability. The different methods have been developed for taking into account the variation of the parameters of their models, which depend on the internal characteristics and the operating conditions of the battery.

This work addresses the main objective that is to develop a Real-time characterization platform with a graphical user interface (GUI) for displaying in real-time the battery three main parameters: open-circuit voltage (OCV), ambient temperature, and the battery current during the charging and discharging process for any type of battery and recording experimental data.

\section{BATTERY}

A battery is anenergy storage device that converts chemical energy included within its active materials directly into electric energy using an electrochemical oxidation-reduction (redox) reaction, while the term battery is often used, the cell is the basic electrochemical unit used to generate or store electric energy.

Each electrochemical cell is made up of two electrodes which are cathode (positive plate), anode (negative plate), and separated by an electrolyte as shown in Fig.1. The electrode materials and electrolyte are selected and organized in such a way that appropriate electromotive force emf (volt) $=\mathrm{dW}$ (joules)/dQ (coulomb) and electric current (measured in amperes) can be generated between the terminals of a battery. The terminal voltage of a cell during neither charging nor discharging process is called the open-circuit voltage (OCV) that equals the emf of the cell. The cell terminal voltage during a discharging is lower than the opencircuit voltage due to internal resistance, whereas the terminal voltage of a charging cell surpasses the open-circuit voltage [3].

The transfer of electrons from one electrode to the other produces the current in the battery. During discharging process, the anode's oxidation reaction generates electrons, however the cathode's reduction reaction consumes these electrons. So, electrons move from the anode to the cathode but they do not return back from the cathode to the anode, instead electrical neutrality is maintained by the movement of ions in the electrolyte [4].

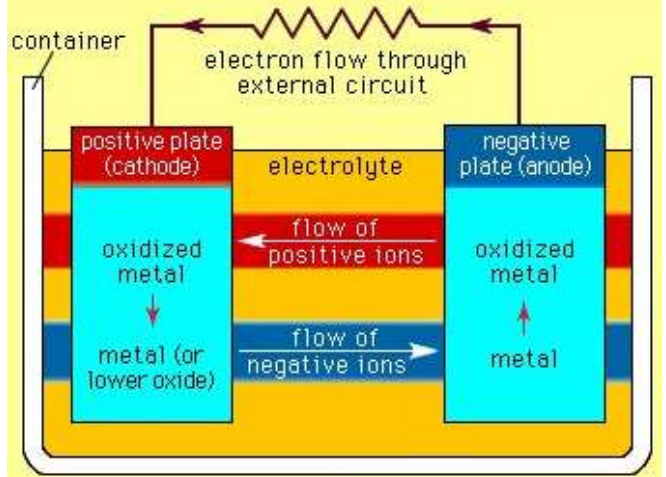

Fig. 1 Basic components of a Typical Electrochemical cell (battery) [5].

\section{TERMS RELATED TO BATTERY}

\section{Capacity}

Capacity indicates the specific electrical energy can be stored in the battery given in ampere-hours (Ah). Theoretical capacity refers to the maximum amount of charge that a battery can drain based on the amount of active material it contains. This capacity is highly dependent on the cell's internal impedance and varies depending on the operating conditions.

$$
Q=\int_{E i}^{E f} I(t) d t(1)
$$

Where: $l(t)$ is current in $(A)$,

$E_{i}, E_{f}$ are the amounts of charges at initial and final states respectively,

Q: Amount of usable electric charge in (Ah or C).

The term nominal capacity represents the capacity measured under nominal conditions. These conditions correspond to a precise protocol, in particular of precise temperature and aging of the battery.

\section{State of Charge (SOC)}

A state of charge (SOC) represents the amount of remaining capacity of a battery incharge-

dischargecyclestothefullchargecapacity as a percentage of its currentcapacity, while the SOE (State of Energy)is a measure for the amount of usable energy (remaining in the battery), a higher SOC and SOE means that higher capacity and energy is stored in the battery [6]. The state of charge at instant $t$ is given by:

$\operatorname{SOC}(t)=\frac{\text { Qremaining }}{\text { Qrated }} \times 100(2)$

Where:Qremainingis the remaining capacity at time $t, Q$ rated is the total capacity.

The Qrated is not only dependent on the temperature but also on the aging. 


\section{State of Health (SOH)}

A State of Health $(\mathrm{SOH})$ is defined as a ratio of full charged capacity to its nominal capacity. The $\mathrm{SOH}$ represents the battery's state between the beginning of life (BoL) and the end of life (EoL) in percentages. In other words, it indicates how much of the battery's useful lifetime has been spent and how much remains before it must be replaced [6]. A used battery's full charge capacity is less than its designed capacity which is given by:

$$
\text { SOH }=\frac{\text { Capacity }(\text { current })}{\text { Capacity }(\text { rated })} \quad \times 100 \quad \%
$$

\section{Depth of Discharge (DoD)}

Depth of Discharge (DoD) is the percentage of capacity depleted from a fully charged battery. It is another method to indicate a battery's State of Charge (SoC). The Depth of Discharge is the complement of State of Charge: as one increases, the other decreases [6]. More DoD in each cycle means the cell is more stressed in that cycle. Furthermore, the number of possible cycles in a battery's lifetime is highly dependent on the DoD, the relationship between SOC and $D O D$ is described as following:

$$
\begin{aligned}
& \operatorname{SOC}(t)+D O D(t)=100 \% \\
& \quad \text { C-Rate }
\end{aligned}
$$

C-rate is defined as the current flowing through the battery divided by the theoretical current draw required by the battery to supply its nominal rated capacity in one hour. It has the units $\mathrm{h}-1$ [8].

\section{Internal Resistance}

During the operation of battery, when the battery current flows, there exists a difference between the actual voltage and the opencircuit voltage, which can be used to characterize the resistance of the battery. This resistance depends on many parameters such as temperature, state of charge, and also electrochemical aging.

$$
R(t)=\frac{\Delta \mathrm{V}}{\Delta \mathrm{I}}=\frac{\mathrm{V}(\mathrm{t})-\mathrm{V}}{\mathrm{I}(\mathrm{t})-I 0}
$$

\section{Efficiency}

The overall battery efficiency is specified by two efficiencies. Firstly, a Coulombic efficiency $(n C)$ is the ratio of the total charge provided by the battery during discharging process to the total charge supplied to the battery during charging process over a full cycle. The losses that lower columbic efficiency is charge losses due to secondary reaction. Secondly, a voltage efficiency $(n \mathrm{U})$ is determined by the voltage difference between the charging voltage and battery voltage during discharge. The efficiency factor is commonly measured by Coulombicefficiency which is given by:

$$
\eta \mathrm{C}=\frac{Q(\text { discharge })}{Q(\text { charge })} * 100 \%
$$

Where: $\mathrm{Q}$ (discharge) is the total electric charge extracted from battery during discharge in $(\mathrm{C})$; and $\mathrm{Q}$ (charge) is the total electric charge supplied to the battery to fully charge in $(C)$.

\section{CHARACTERIZATION PROCEDURES}

Before investigating any characterization of battery, the cell is charged using first constant current (CC) at $1 \mathrm{~A}$ and after constant voltage (CV) charging method until the current drained from the charging source is less than $0.02 \mathrm{~A}$. After complete charging, the cell is left in open circuit for one hour to reach electrochemical equilibrium. The cell is completely discharged in the tests but in much application the cell/battery is discharged to $5-10 \%$. The complete discharge of the cells will intensely shorten the life cycle, thus, a limit for the Depth of Discharge (DoD) is imposed to extend the life cycle.

\section{Capacity test}

The cell capacity represents the maximum amount of energy that can be extracted from the cell under certain specific conditions. The actual energy storage capabilities of the cell can vary significantly from the "nominal" rated capacity, as the cell capacity depends strongly on its age, the charging or discharging states and the temperature. A nominal capacity value is always provided by the manufacturer in the datasheet; however, a test should be performed to calculate a more reasonable value, the actual capacity of the cell, to be employed inside the cell model. The cell capacity given by the manufacturers is obtained by discharging the cell at the maximum constant current that a cell can supply for 20 hours at $20^{\circ} \mathrm{C}$. Several discharging tests can be performed on the cell; therefore a constant current discharge at different values is applied, until the lower voltage threshold is reached. The voltages waveforms are depicted in Fig.2. The value of the capacity used in the model is the average of the capacity obtained for different constant discharging currents.

\section{Current pulse test}

This test permits the proper characterization of the battery with discharging current pulses while observing its voltage response. During this test, pulses must be performed over the 
whole battery range of the State Of Charge (SOC).

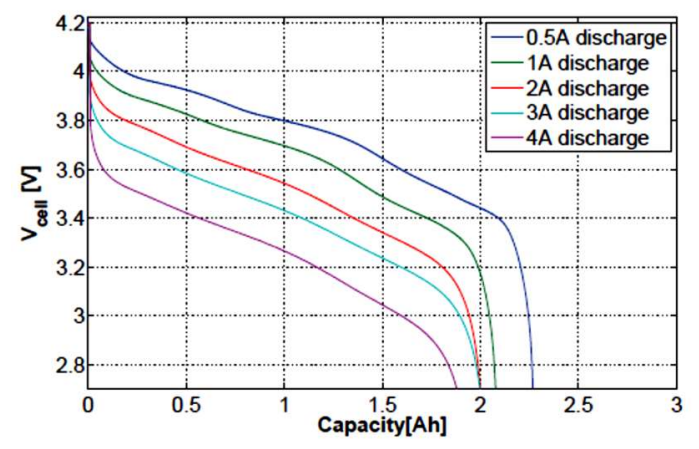

Fig.2 Cell capacity for different values of discharge constant current.

The main objective of this test implementation is to obtain the relationship between the battery Open Circuit Voltage and state of charge (SOC). It consists of fully charge the battery with the standard charging method. After complete charging, the battery is left in open circuit for one hour to reach electrochemical equilibrium. Afterwards series of discharging current pulses at $0.5 \mathrm{C}$-rate from $100 \%$ to $0 \%$ state of charge (SOC) are applied for 2 minutes separated by 8 minutes rest period in between until the lower threshold voltage (cut-off voltage) is reached. For discharging the cell from $100 \%$ to $0 \%, 42$ discharging pulses were applied, one pulse discharge the cell approximately $2.4 \%$. Figure 3 shows the Lithium-ion battery voltage and the values for the open circuit voltage.

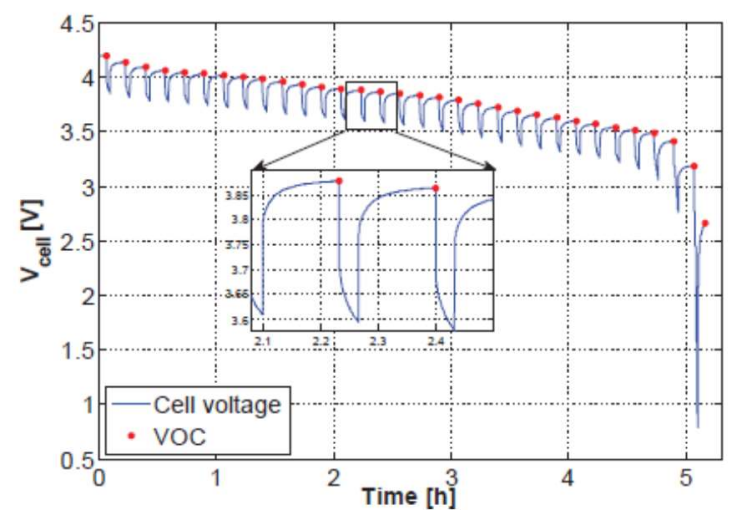

Fig. 3 The battery voltage and the values for the open circuit voltage (Lithium-ion battery) [4].

\section{PLATFORM IMPLEMENTATION}

Real-time monitoring systems are generally based on computer systems that can monitor internal and external environmental variable parameters. A data acquisition system that has been developed using Arduino Uno board associated with PC and LabVIEW acquires battery open-circuit voltage, charging and discharging currents, ambient temperature. This system is a real-time platform for reading, processing, monitoring, and storing the acquired data for further analysis. The developed system is useful for any battery type characterization [9].

\section{Hardware Part}

The general block diagram of the developed Platform is shown in Fig. 4. It is mainly based on a control board for data acquisition, a host computer for monitoring and processing experimental data, and a programmable power supply for battery charging, a load for cell discharging. A computer is connected to the board (Arduino Uno) via USB cable and is also used to control and monitor the testing bench. Acquired Data can be saved in the PC in excel file.

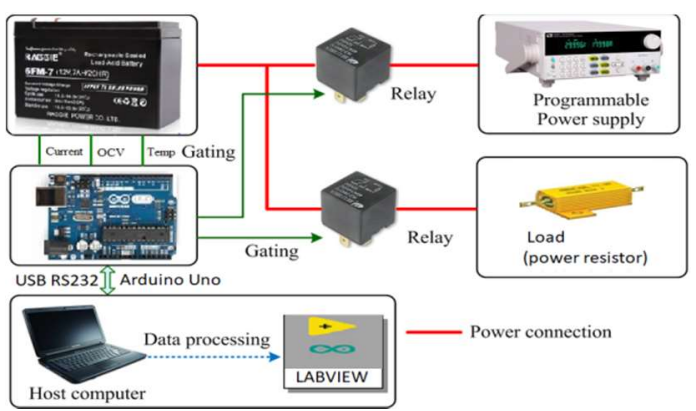

Fig. 4General Block diagram of Real-time battery characterization platform.

A Sealed-Lead acid battery (REGGIE 6FM-7) under test is connected in series with HallEffect current sensor, which acquires the current image value. The relays (RL1 and RL2) are controlled by PC through Arduino, which leads to control the discharging and charging phases and their periods.

Discharge phase: Relay RL2 is switched OFF to disconnect the power supply. Relay RL1 is switched ON, it implies that a load is connected to the RL1 NC pin to drain the battery and record discharge current; after a certain discharge period $\left(t_{1}\right)$ defined by the user, RL1 is switched OFFto disconnect the load and connect the voltage sensing circuit while waiting for battery relaxation time $\left(\mathrm{t}_{2}\right)$ it measures open-circuit voltage. The process is repeated continuously until the battery is discharged.

Charging phase: during the charging process, RL1 is turned OFF to disconnect the load. However, RL2 is switched ON to connect a power supply to charge the battery and record the charging current. After a certain charging period $\left(\mathrm{t}_{3}\right)$ defined by the user, RL2 is switched OFF to disconnect the power supply 
and connect the voltage sensing circuit while waiting for battery relaxation time $\left(t_{4}\right)$ before measuring open-circuit voltage. The process is repeated continuously until the battery is fully charged.

The ambient temperature is being acquired continuously during both charging and discharging processes using a thermal sensor.

\section{Software Part}

The software program used for data acquisition as well as the control of the test bench has been developed using LabVIEW [11].

The LabVIEW front panel of the battery characterization system has three main components:

- Control panel

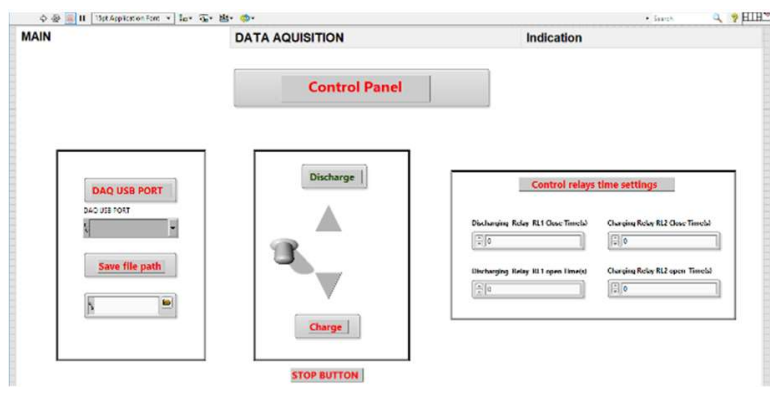

Fig. 5 Platform control panel.

The basic function of the control panel is to wait for user commands, so that the software performs them. It has:

1) DAQ USB PORT to select the acquisition channels.

2) Saving file path for recording instantaneous data using Excel.

3) Charge / Discharge: User selects either battery charging or discharging.

4) Control relays time settings the user: can insert relays triggering time and hold time in (ms).

In this tab shown in Fig.6, measured battery parameters are displayed in real-time including:

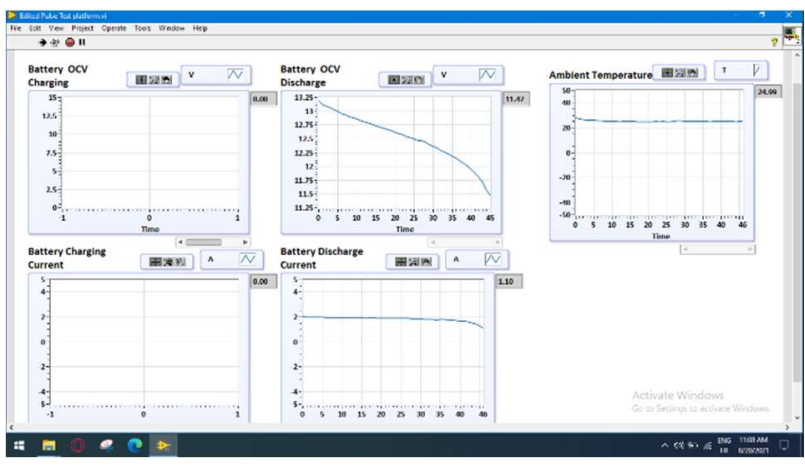

Fig. 6 Acquired data graphs.

1- Open circuit voltage (Charge / discharge).

2- Charging / discharging currents.

3- Ambient temperature.

- Numerical data indication

This tab gives a provision to the user to continuously observe the numerical values for the measured parameters in real-time.

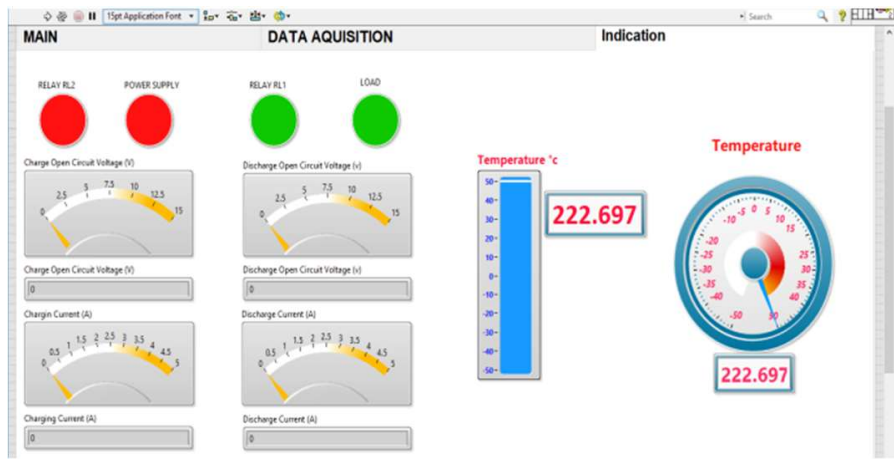

Fig. 7 Numerical data and control indication.

The software program based on LabVIEW that has been developed using a flowchart shown in Fig.8,is shown in Fig.9 


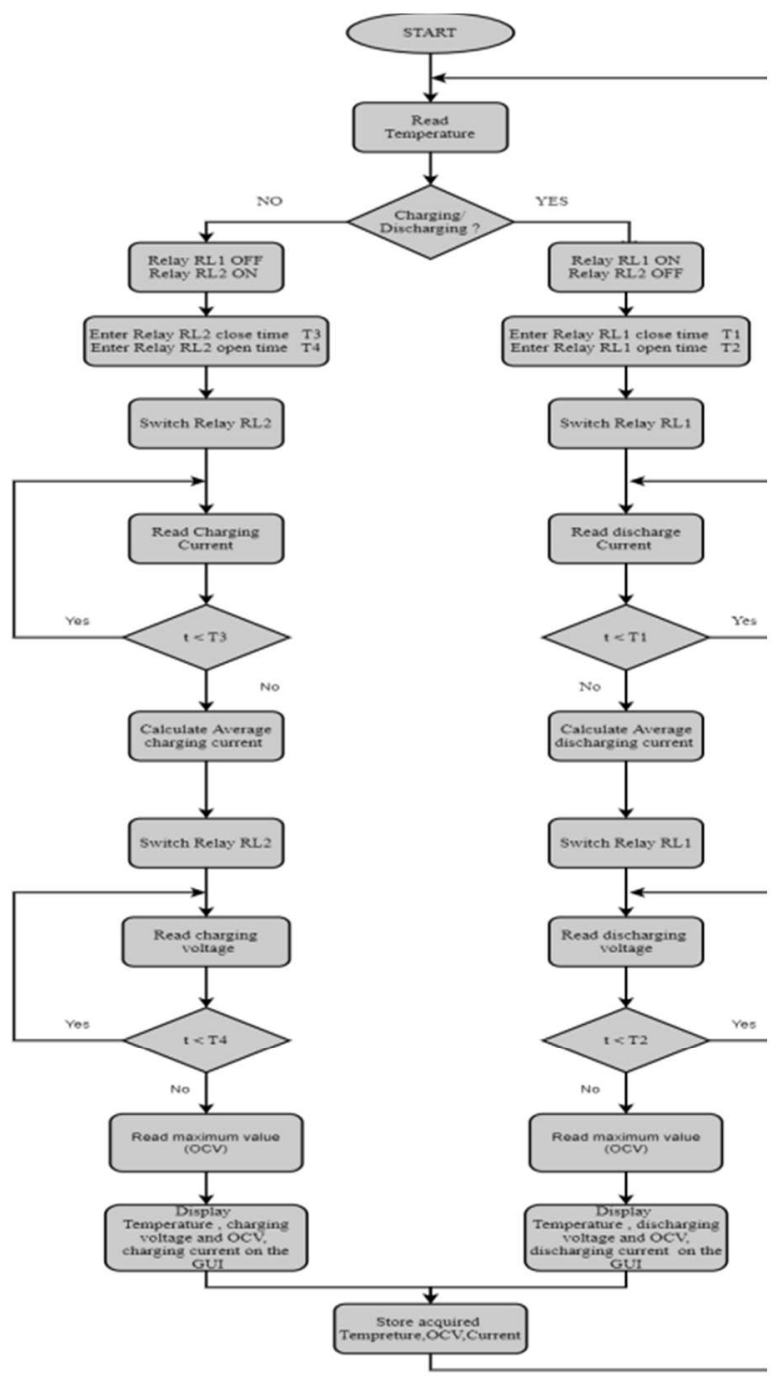

Fig. 8 System Program flowchart. system can monitor voltage, current of the battery, and ambient temperature during charging and discharging process.The developed platform can display the measured valuesusing the system $\mathrm{GUI}$ and save them in excel file, which in turn will be used for battery state of charge (SOC) estimation and aging studies.A Sealed-Lead acid battery (REGGIE $6 \mathrm{FM}-7)$ is used to test this platform.

\section{Capacity Discharge test}

The discharge of Lead-Acid battery is tested with different discharge current rates and temperatures. The timing is set as follows: 2 minutes for battery discharging and current measurement simultaneously and 10 minutes for battery relaxation before measuring battery OCV.The obtained results shown in Fig.10 fordischarge that is investigated on $3.3 \Omega$ Load, $0.57 \mathrm{C}$-rate, at the temperature $25^{\circ} \mathrm{C}$, and in Fig.11 for discharge of different C-rates.

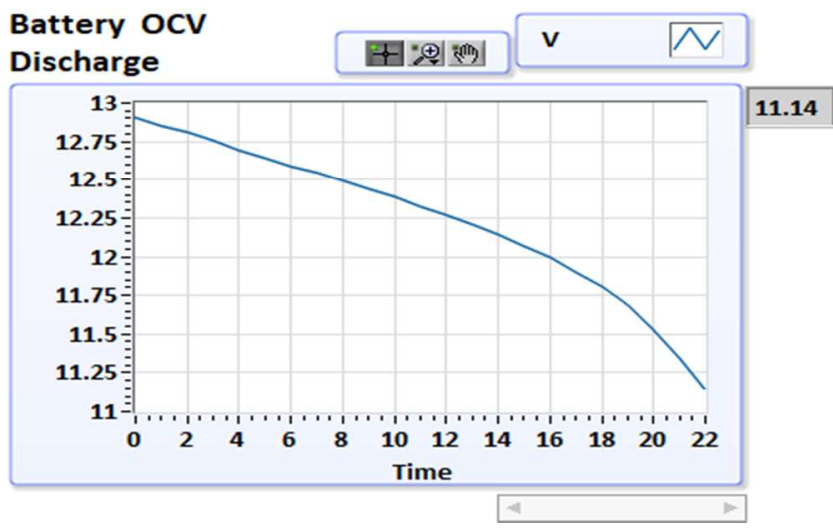

Fig.10 The battery discharge OC voltage (Lead-acid battery).

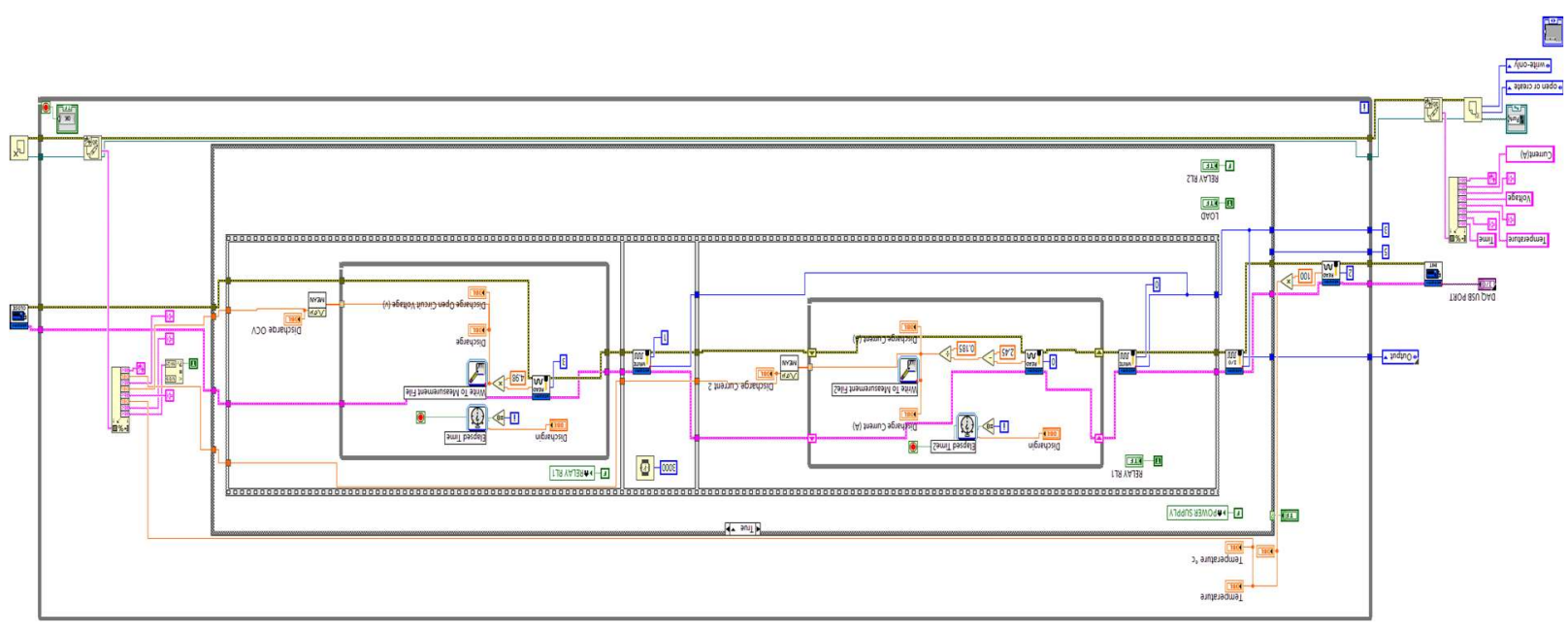

Fig. 9 The LabVIEW software program.

\section{PERFORMANCE EVALUATION}

The battery characterization system has been tested and calibrated in the laboratory, this 


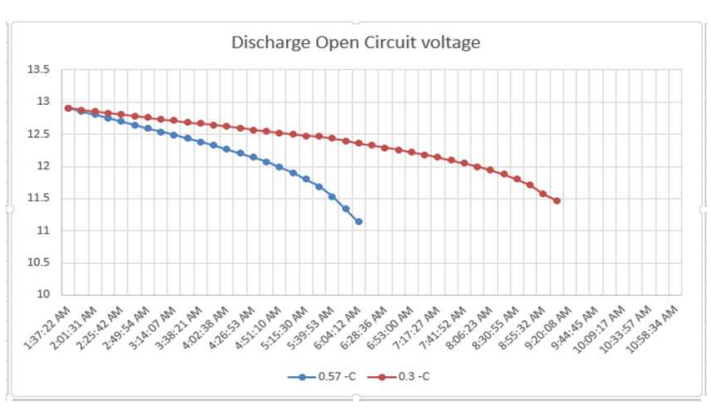

Fig. 11 Battery discharge OCV a function of

C-rate and time.

\section{Current pulse test}

This test permits the proper characterization of the battery with discharging current pulses while observing its voltage response.

The open circuit voltage (OCV) of the battery represents the value of the voltage when the battery is left in the open circuit condition after a discharge pulse. Therefore, after discharge pulse, the battery terminal voltage will gradually rise to a steady value after the load is removed. The battery terminal voltage extracted values are plotted in Fig. 12.

It can be noticed that the trends of the obtained curves shown in figures 10 and 11 are similar to the curves of Fig.2 and the trend of experimental curve of Fig.12 is similar to the curve shown in Fig.3.

\section{CONCLUSION}

The low cost proposed platform(both hardware and software part) implementation has been presented, as well as the conducting experimental test of different functionalities during both charging and discharging processes. The developed system is valid for the characterization of any battery type.

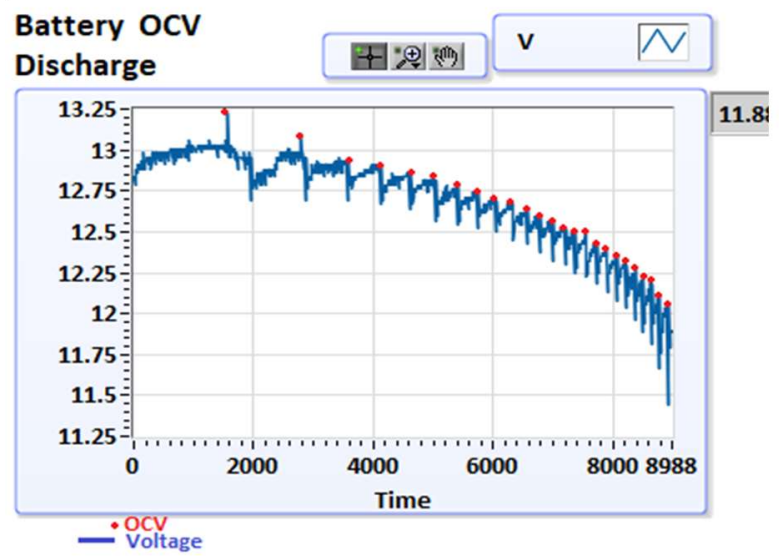

Fig.12 The battery voltage and the values for the open circuit voltage (Lead-acid battery).
It can be noted that the obtained curves are in agreement with previous published curves of both charging and discharging processes. This developed platform can contribute in further performance enhancements and reliability of this technology.

\section{References}

[1] Kong Soon Ng, Chin-Sien Moo, Yi-Ping Chen, and Yao-ching Hsieh,"Enhanced coulomb counting method for estimating state-ofcharge and state-of-health of litihium-ion batteries," Journal of Applied Energy, Vol.86, No. 9, pp. 1506-1511, Sep. 2009. DOI: https://doi.org/10.1016/j.apenergy.2008.11.02 1

[2] S. Lee, J. Kim, J. Lee, B. H. Cho, "State-ofcharge and capacity estimation of lithium-ion battery using a new open-circuit voltage versus state-of-charge", Journal of Power Sources, 185(2), pp.1367-1373, 2008. DOI: https://doi.org/10.1155/2018/5218205

[3] Electrochemical battery - UK Essays [online] Available at: https://www.ukessays.com/essays/chemistry/ electrochemical-battery.php, [Accessed : april. 18, 2021]

[4] T. Azzouni, "Real Time Characterization of Lithium-Ion Battery", Master thesis, FS, University M'hamed Bougara Boumerdes, 2021.

[5] Battery - Encpedica Britannica [online] Available at: https://www.britannica.com/technology/battery -electronics/Primary-batteries

[Accessed : May 10, 2021]

[6] M. Dubarry, V. Svoboda, R. Hwu, and B.Y. Liaw, "Capacity loss in rechargeable lithium cells during cycle life testing: The importance of determining state-of-charge", Journal of Power Sources, 174(2), pp. 1121-1125, 2007.

[7] S.Bhadra, B. J.Hertzberg, A. G.Hsieh, M. Croft, J. W.Gallaway, B. J. Van Tassell, D.A. Steingart,"The relationship between coefficient of restitution and state of charge of zinc alkaline primary LR6 batteries", Journal of Materials Chemistry A, 3(18), pp. 93959400,2015.DOI: https://doi.org/10.1039/C5TA01576F

[8] MIT Electric Vehicle Team, "A Guide to Understanding Battery Specifications", December 2008.

[9] M. A. Litoufi, N. Tair, "Design and Implementation of a Real-Time Battery Characterization Platform", Master thesis, IGEE, University M'hamed Bougara Boumerdes, 2021.

[10] A. Mati, B. Bousaadia, H. Bentarzi, "A New Model of Numerical MHO Distance Relay Associated with Power Swing Detector", Alqerian Journal of Signals and Systems . Vol.1, $\mathrm{N}^{\circ}$ 2, pp.121-128. 2016.DOI:

https://doi.org/10.51485/ajss.v1i2.26 